\title{
PENGARUH PENGGUNAAN MEDIAL ARCH SUPPORT TERHADAP KESEIMBANGAN DINAMIS PADA KAKI PES CAVUS PADA ORANG TUA LANJUT USIA (LANSIA)
}

\author{
Muhammad Fathi*, Cica Tri Mandasari Ningsih ${ }^{2}$ \\ Poltekkes Kemenkes Surakarta Jurusan Ortotik Prostetik
}

\begin{abstract}
Background: According to The World Health Organization (WHO), in the Southeast Asia the Elderly population is 8\% or around 142 million people. Feet function for shock absorber, Generally there are three types of foot structure, namely neutral or normal, flat foot, and cavus foot. The cavus foot will improve performance on the musculoskeletal structure to maintain postural stability and balance due to midfoothypomobile. As a result, cavus foot cannot distribute body weight evenly along the metatarsal heads and the lateral side of the foot, lowering the sensory plantar input and significantly the pressure on the foot is greater than the other foot postures. Methods: The research design used was quasy experiment with cross sectional design. dynamic balance measurement with TUG test The study was conducted in April - July 2018 at the Posyandu at the elderly Klodran, Colomadu, Karanganyar. with a sample of 20 elderly. data collection using the wetfootprint pre test and post test with medial arch support. Results: the results of p value 0,000<0,05 so that there is a difference in the dynamic balance in the elderly before and after being given Medial arch support. can also see from the mean acquisition value of the elderly before using the medial arch support of 13.7 while after using the medial arch support the mean gain of 13.2.Conclusion: the results of a study of 20 elderly people showed that dynamic balance in the legs of pes cavus in the elderly (elderly). before using the medial arch support higher than the dynamic balance at the foot of pes cavus in the elderly (elderly).
\end{abstract}

Keywords: Cavus Foot, Medial Arch Support

PENDAHULUAN

Menurut WHO, di kawasan Asia Tenggara populasi Lansia sebesar $8 \%$ atau sekitar 142 juta jiwa. Pada tahun 2050 diperkirakan populasi lansia meningkat 3 kali lipat dari tahun ini. Pada tahun 2000 jumlah lansia sekitar 5,300,000 (7,4\%) dari total polulasi, sedangkan pada tahun 2010 jumlah lansia 24,000,000 (9,77\%) dari total populasi, dan tahun 2020 diperkirakan jumlah lansia mencapai $28,800,000(11,34 \%)$ dari total populasi. Sedangkan di Indonesia sendiri pada tahun 2020 diperkirakan jumlah lansia sekitar 80.000.000 (Kementerian Kesehatan Republik Indonesia, 2013). Namun hal ini mempunyai dampak demografis atau piramida penduduk berupa peningkatan proporsi lansia. Terkait dengan proses penuaan, sifat otot turun sekitar 30-50\% antara usia 40 - 80 tahun. Proses ini akan berkaitan dengan proses degenerative bentuk pelayanan kesehatan, karena kehidupan lansia mempunyai masalah $40 \%$ tentang kesehatan seperti gangguan mobilitas (Maryatun, 2014). Gangguan mobilitas pada lansia sangat berpengaruh terhadap 
keseimbangan dibanding dengan usia produktifitas. Penurunan fungsi tubuh karena proses penuaan dapat menyebabkan berkurangnya rentang gerak dan berkurangnya kekuatan otot.

Umumnya ada tiga jenis struktur kaki yaitu netral atau normal, flat foot, dan cavus foot. Normal foot memiliki normal struktur anatomis dengan ligamen yang kuat dan tinggiarkus yang normal pada arkus transversal dan arkus longtidinal yang memberikan stabilitas postural yang baik.Pada flat foot akan terlihat flat pada arkus longitudinal medial, eversi calcaneal, forefoot valgus, dan hypermobile midfoot. Pengaruh dari postur ini menyebabkan head of talusb erpindah ke medial dan posterior dari navicular. Perubahan ini dapat meregangkan ligamen dan tendon dari otot tibialis posterior, yang berpotensi untuk meningkatkan penurunan arkus longitudinal medial dan memerlukan kinerja yang lebih besar pada sistem neuromuskular untuk menstabilkan kaki dan berdiri tegak. Sebuah penelitian telah menunjukkan bahwa flat footakan menyebabkan masalah mekanis di pinggang, pinggul, dan sendi lutut termasuk eversi calcaneal yang berlebihan 2-3 derajat yang selanjutnya dapat menyebabkan cedera berlebihan. Sebaliknya, cavus foot juga dikenal sebagai arkuskaki tinggi yang disetai dengan peningkatan arkus longitudinal medialyang terlalu tinggi, inversi calcaneal, dan forefoot varus. Cavus footakan meningkatkan kinerja pada struktur muskuloskeletal untuk menjaga stabilitas postural dan keseimbangan karena midfoothypomobile. Akibatnya, cavus foottidak dapat mendistribusikan berat tubuh secara merata di sepanjang metatarsal headsdan sisi lateral foot, menurunkan input plantar sensoris dan secara signifikan tekanan pada footlebih besar daripada postur kaki yang lainnya. Namun, tidak seperti flat foot, cavus foot dapat memberikan rigid lever untuk daya penggerak namun tidak efisien sebagai shock absorber. Penelitian sebelumnya telah melaporkan bahwa 23 - 60\% subyek dengan cavus foot mengalami nyeri kaki dikaitkan dengan penurunan kontrol mediolateral terhadap tungkai, berpotensi meningkatkan risiko cedera anggota badan. Cavus foot dan flat foot tersebut mempunyai gangguan mekanis yang lebih besar daripada kaki normal, terutama pada keseimbangan saat melakukan aktivitas dengan menumpu beban (Justine, 2016).

\section{Lansia}

Lansia merupakan tahap lanjut dari suatu proses kehidupan yang ditandai dengan penurunan kemampuan tubuh untuk beradaptasi dengan stress lingkungan dan bukan merupakan suatu penyakit. Proses penuaan akan terlihat sejak umur 45 tahun dan timbul masalah pada umur 60 tahun. World Health Organisation (WHO) menggolongkan usia lanjut menjadi 4 yaitu : usia pertengahan (middle age) adalah 45-59 tahun, lanjut usia (elderly) adalah 60-74 tahun, lanjut usia tua (old) adalah 7590 tahun dan usia sangat tua (very old) diatas 90 tahun (Nugroho, 2008) (Yuliniarsi, 2014).

\section{Pes Cavus}

Cavus foot pes cavus adalah kondisi dimana lengkung kaki tampak berlebih yang ditandai dengan sedikit atau tidak menyentuhnya arkus longitudinalis lateralis ke tanah ketika diberi beban oleh tubuh, yang biasanya pada orang normal arkus longitudinalis lateralis tampak 
menyentuh tanah (Nurohman, 2017). Cavus foot ditandai dengan terlalu tingginya arkus medialis disertai dengan supinasi kaki, varus hindfoot dan atau varus forefoot. Jika dilihat dari bagian belakang foot akan terlihat mengalami varus dan inversi pada sendi subtalar. Cavus foot dapat menjadi faktor resiko terjadinya deformitas yaitu hammertoes danclaw toe(Hillstrom, 2013). Cavus foot cenderung akan menyebabkan keausan sol sepatu yang berlebihan pada tumit bagian luar karena terdapat dorongan weight bearing yang lebih ke sisi lateral (Asicstiger, 2017).
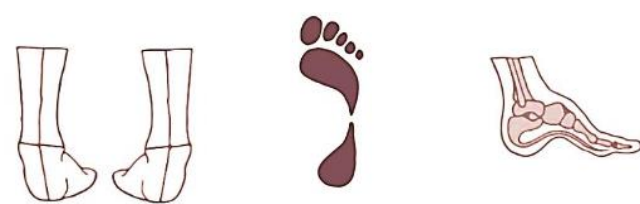

Gambar 1. Cavus foot (Pthealth, 2016)

\section{TUG (Timed Up and Go Test)}

TUG (timed up and go test) adalah suatu alat ukur untuk menilai keseimbangan pada lansia, yaitu untuk mengukur kecepatan terhadap aktivitas yang mungkin menyebabkan gangguan keseimbangan (Bansal, 2013) (Radisca, 2016). Cara pemeriksaan TUG, lansia duduk pada kursi dengan bersandar. Lutut fleksi $90^{\circ}$, lengan bersandar. Selanjutnya lansia berdiri, berjalan 3 meter (10 feet), berputar, jalan kembali menuju kursi dan duduk kembali bersandar. Waktu diukur dengan stopwatch mulai dari awal berdiri sampai duduk bersandar kembali. Saat berjalan dapat menggunakan alas kaki atau tanpa alas kaki, dengan alat bantu atau tanpa alat bantu, tetapi tidak boleh dibantu oleh orang lain (Utomo, 2009). Pasien tidak diperbolehkan mencoba atau berlatih lebih dulu, stopwatch mulai menghitung setelah pemberian aba-aba mulai dan berhenti menghitung saat subjek kembali pada posisi awal atau duduk (Decungkringo, 2012).

Tabel 1. Nilai Normal TUG Tes Pada Lansia (Jacobs \& Fox. 2008 )

\begin{tabular}{cccc}
\hline \multicolumn{4}{c}{ Nilai Normal } \\
\hline Umur & $\begin{array}{c}\text { Jenis } \\
\text { kelamin }\end{array}$ & $\begin{array}{c}\text { Waktu } \\
\text { Rata-rata }\end{array}$ & $\begin{array}{c}\text { Jarak } \\
\text { normal }\end{array}$ \\
\hline $60-69$ & L / P & 8 detik & 4-12 detik \\
$70-79$ & L & 9 detik & 3-15 detik \\
$70-79$ & P & 9 detik & 5-13 detik \\
$80-89$ & L & 10 detik & 8-12 detik \\
$80-89$ & P & 11 detik & 5-17 detik \\
\hline
\end{tabular}

Berdasarkan sensitivitas dan spesifikasi penilaian dari Time Up and Go Test diatas disimpulkan jika skor $<14$ detik; $87 \%$ maka tidak ada resiko tinggi untuk jatuh, sedangkan jika skor $\geq 14$ detik; $87 \%$ resiko tinggi untuk jatuh (Jacobs \& Fox. 2006).

\section{METODE PENELITIAN}

Rancangan penelitian yang digunakan adalah quasy experiment dengan desain cross sectional hubungan pes cavus pada foot terhadap keseimbangan dinamis pada lansia untuk dilakukan pengukuran keseimbangan dinamis dengan TUG test. Penelitian dilakukan di Posyandu lansia Klodran, Colomadu, Karanganyar sampel yang didapatkan 20 lansia. Pada tahap pelaksanaan dimulai dengan pendataan usia dan pengambilan plantar foot print untuk mengetahui tipe arkus cavus foot pada lansia. Setiap subjek yang sesuai dengan kriteria inklusi dilakukan pengukuran keseimbangan dinamis. Alat yang digunakan untuk mengukur keseimbangan dinamis antara lain : kursi bersandar tanpa pegangan tangan, penanda area garis start dan finish jarak 3 $\mathrm{m}$, stopwatch, dan meteran. Lintasan yang digunakan untuk pelaksanaan pengukuran 
keseimbangan adalah lintasan yang datar dan tidak licin sehingga meminimalkan adanya gangguan saat melakukan tes keseimbangan.

Untuk prosedur test dijelaskan seperti berikut, awalnya lansia duduk pada kursi bersandar tanpa pegangan tangan. Lutut fleksi $90^{\circ}$. Selanjutnya peneliti memberi aba-aba untuk subjek berjalan lurus dari titik A menuju titik B dengan jarak 3 meter, berputar $180^{\circ}$, jalan kembali menuju kursi dan duduk kembali bersandar. Penilaian dari Time Up and Go Test jika skor < 14 detik maka tidak ada resiko tinggi untuk jatuh atau dikatakan seimbang, sedangkan jika skor $\geq 14$ detik beresiko tinggi untuk jatuh atau dikatakan tidak seimbang

\section{HASIL PENELITIAN}

Tabel 2. Karakteristik Jenis Kelamin, Umur,

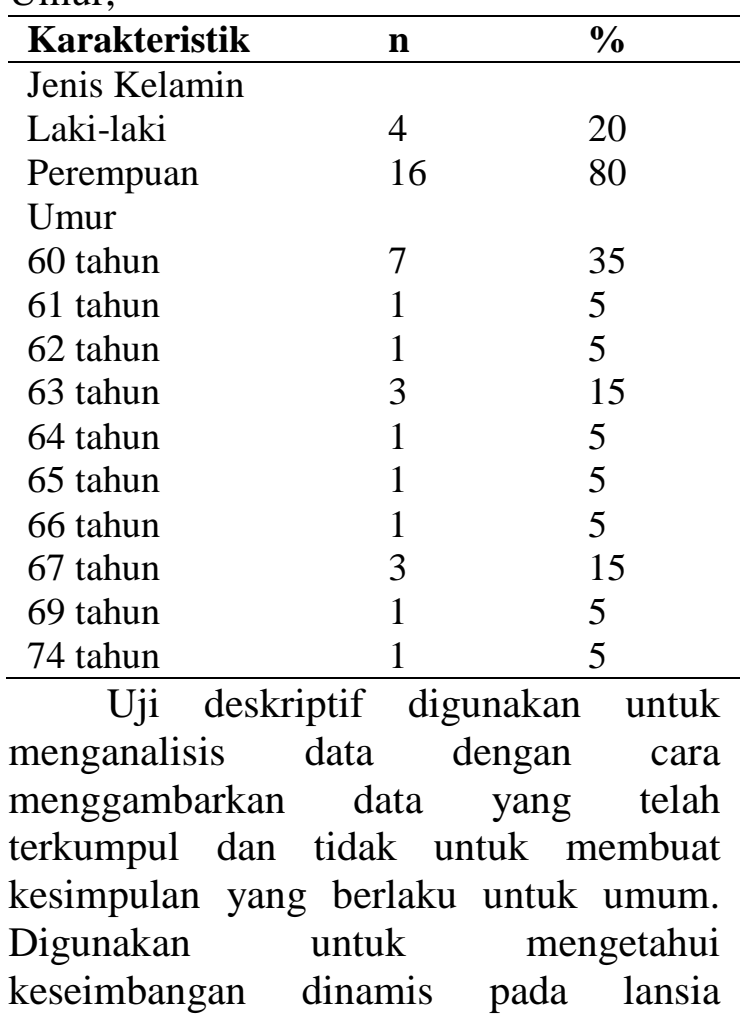

sebelum dan sesudah menggunakan medial arch support.

Tabel 3. Uji Deskriptif

\begin{tabular}{ccccc}
$\begin{array}{c}\text { Keseimbangan } \\
\text { Dinamis }\end{array}$ & Min & Max & Mean & $\begin{array}{c}\text { Standar } \\
\text { Deviasi }\end{array}$ \\
\hline pre & 12,3 & 15 & 13,7 & 0,79424 \\
Post & 11,2 & 15 & 13,2 & 1,04593 \\
\hline Uji normalitas & bertujuan & untuk \\
mengetahui apakah data yang akan \\
dianalisis, yaitu Keseimbangan dinamis \\
pada lansia memenuhi persyaratan uji \\
statistica parametric atau non parametrik. \\
Uji statistik yang dilakukan adalah uji \\
normalitas untuk menentukan data \\
berdistribusi normal atau tidak. Jika data \\
sampel > 50 maka dilakukan uji \\
Kolmogorov - Smirnov, apabila data \\
sampel < 50 maka dilakukan uji Shapiro- \\
Wilk.
\end{tabular}

Tabel 4. Uji Normalitas

\begin{tabular}{cccccccc}
\hline & \multicolumn{3}{c}{$\begin{array}{c}\text { Kolmogorov- } \\
\text { Smirnova }\end{array}$} & \multicolumn{3}{c}{ Shapiro-Wilk } \\
\cline { 2 - 7 } pretest & Statistic & df & Sig. & Statistic & df & Sig. \\
\cline { 2 - 8 } posttest &, 121 & 20 &, $200^{*}$ &, 939 & 20 &, 230 \\
\hline
\end{tabular}

Uji hipotesis yang digunakan adalah uji Paired Sample $T$ - Test untuk mengetahui ada atau tidaknya pengaruh penggunaan medial arch support terhadap keseimbangan dinamis pada orang tua lansia. Hasil uji hipotesis dapat dilihat pada table dibawah ini

Tabel 5. Uji Hipotesis

\begin{tabular}{lccc}
\hline & Mean & $\begin{array}{c}\text { Std. } \\
\text { Deviation }\end{array}$ & Sig. \\
\hline Pre Test & 13,7350 & 0,79424 & .000 \\
Post Test & 13,2350 & 1,04593 & \\
\hline
\end{tabular}

Hasil penelitian menunjukkan ratarata pada kelompok pre test $(13,73)$ sedangkan rata-rata pada kelompok post 
test $(13,23)$. Dan nilai rata-rata hasil uji statistic dengan Paired Sample T - Test menunjukkan $p$ value $0,000<0,05$ sehingga terdapat pengaruh penggunaan Medial arch support terhadap keseimbangan dinamis pada kaki pes cavus lansia.

\section{PEMBAHASAN}

Uji hipotesis yang dilakukan menggunakan uji paired sample $t$ - test menunjukkan ada pengaruh yang signifikan antara penggunaan medial arch support terhadap keseimbangan dinamis pada kaki pes cavus pada orang tua (lansia). Hal ini dilihat dari hasil analisis data penelitian menunjukkan perolehan nilai probabilitas (p) 0,000. Probabilitas < 0,05 yang berarti hal tersebut menunjukkan ada pengaruh yang signifikan antara penggunaan medial arch support terhadap keseimbangan dinamis pada kaki pes cavus pada orang tua (lansia). Selain melihat dari hasil analisis nilai probabilitas (p) bisa juga melihat dari nilai perolehan mean pada lansia sebelum menggunakan medial arch support sebesar 13,7 sedangkan setelah menggunakan medial arch support perolehan mean sebesar 13,2. Hal ini menunjukkan bahwa keseimbangan dinamis pada kaki pes cavus pada orang tua (lansia). Sebelum menggunakan medial arch support lebih tinggi disbanding dengan keseimbangan dinamis pada kaki pes cavus pada orang tua (lansia) sesudah menggunakan medial arch support, sehingga dalam hal ini penggunaan medial arch support berpengaruh signifikan dalam keseimbangan dinamis pada kaki pes cavus pada orang tua (lansia).

Hasil uji hipotesis yang signifikan tersebut bisa dipengaruhi oleh latar belakang subjek diantaranya usia lansia dan jensi kelamin. Usia lansia yang mengikuti penelitian ini berkisar antara umur 60 tahun hingga 74 tahun. Dimana sebanyak 16 subjek (80\%) adalah perempuan.dengan mean pre test sebesar 13,7 .

Hasil hipotesis data penelitian pengaruh medial arch support terhadap keseimbangan dinamis pada lansia menunjukan nilai significacy 0,000 $(\mathrm{p}<0,005)$ yang menunjukan bahwa terdapat pengaruh penggunaan medial arch support terhadap keseimbangan dinamis pada lansia.

Faktor-faktor yang mempengaruhi keseimbangan dinamis pada penelitian ini berdasarkan faktor fisik yaitu usia karena keseimbangan akan mengalami penurunan seiring proses penuaan. Hal ini dikemukakan oleh pujiastuti (2005) bahwa proses penuaan akan kelihatan sejak umur 45 dan timbul masalah pada umur 60 tahun. Pada lansia akan terjadi penurunan berbagai organ, fungsi dansistem tubuh yang bersifat alamiah atau fisiologis. Penurunan tersebut disebabkan berkurangnya jumlah dan kemampuan sel tubuh. Guccione (2005) juga menyatakan bahwa semua komponen kontrol postural yang meliputi sensoris, efektor dan proses di susunan saraf pusat, akan mengalami penururnan disebabkan bertambahnya usia. Faktor aktifitas fisik juga berpengaruh terhadap keseimbangan dinamis.

\section{KESIMPULAN DAN SARAN}

Berdasarkan penelitian yang didapatkan hasil $p$ value $0,000<0,05$ sehingga dinyatakan terdapat perbedaan keseimbangan dinamis pada lansia sebelum dan sesudah diberikan Medial arch support. bisa juga melihat dari nilai 
perolehan mean pada lansia sebelum menggunakan medial arch support sebesar 13,7 sedangkan setelah menggunakan medial arch support perolehan mean sebesar 13,2. Hal ini menunjukkan bahwa keseimbangan dinamis pada kaki pes cavus pada orang tua (lansia) sebelum menggunakan medial arch support lebih tinggi dibanding dengan keseimbangan dinamis pada kaki pes cavus pada orang tua (lansia)

Berdasarkan penelitian yang telah diteliti, peneliti memberikan saran untuk penelitian selanjutnya untuk menambah jumlah subjek yang akan diteliti, peneliti diharapkan memfollow up pasien sesering mungkin, peneliti meminta pasien untuk bersikap jujur saat dilakukan penelitian dan lebih teliti sehingga faktor yang dapat mempengaruhi keseimbangan dinamis dapat disertakan dalam penelitian.

\section{DAFTAR RUJUKAN}

Algazali, M. A 2016. Pengaruh Tandem Walking Exercise Terhadap Keseimbangan Dinamis Pada Lansia Usia 60-74 Tahun. Fakulitas Ilmu Kesehatan Universitas Muhammadiyah Surakarta

Amirullah, M. Z 2016. Hubungan Struktur Pedis Dengan Kecepatan Lari 60 Meter Pada Siswa Sma Negeri 3 Semarang. Universitas Diponegoro

Anggraini, F. S .2016. Pengaruh Latihan Handstand Terhadap Peningkatan Keseimbangan Statis Pada Anak Laki-Laki Usia 8-9 Tahun Di Sdn 2 Getas Blora Jawa Tengah. Fakultas Ilmu Kesehatan Universitas Muhammadiyah Surakarta

Asicstiger. 2017. Understanding Pronation. ASICS Europe. https://www.asics.fi/running/knowle dge/understanding-pronation/I diakses 5 agustus 2018

Bertani, M., Soares, D., Rocha, E. \& Machado, L 2017. Foot Arch Differences in Elderly People at Standing : Considering Gender and Age. University of Porto.

Brampton Foot Clinic. 2016. Flat Feet or High Arches. http://www.bramptonfootclinic.com/ flat-feet-high-arches/ diakses 10 agustus 2018

Decungkringo. 2012. Keseimbangan Tubuh (Body Balance). Diakses pada 31Maret 2012 di Health News. https://decungkringo.wordpress.com /tag/tug-test/

Dewi, A 2015. Perbedaan Aquatic Exercise Therapy Dan Senam Aerobic Low Impact Dalam Meningkatkan Keseimbangan Dinamis Pada Lansia Di Banjar Dharma Santi. Universitas Udayana. Bali.

Giovanni, C, D and Justin, G 2007. Foot and Ankle: Core Knowledge in Orthopaedics. ElsevierMosby

Hillstrom, H, J., Song J., Kraszewski, A, P., Hafer J, F., Mootanah, R., Dufour, A, B., Chow, B, S., Deland, J, T (2013). Foot Type Biomechanics Part 1: Structure and Function of the Asymptomatic Foot. National Institutes Of Health.Page 2

Jurnal Olahraga Prestasi. Volume 11, Nomor 2, Juli 2015 hal 97

Justine, M., Ruzali , D., Hazidin, E., Said, A., Bukry, S, A. \& Manaf, H 2016. Range Of Motion, Muscle Length, And Balance Performance In Older Adults With Normal, Pronated, And Supinated Feet. Department Of Physiotherapy, Universiti Teknologi 
MARA: Puncak Alam Campus, 42300 Puncak Alam, Selangor, Malaysia.The Journal of Physical Therapy Science

Kusuma, D, A, N 2017. Pengaruh Pemberian Strengthening Exercise Ekstremitas Bawah Regio Foot Dan Ankle Terhadap Keseimbangan Statis Pada Anak Flat Foot Usia 6-9 Tahun Di Sdn 2 Gonilan Kartasura. Universitas Muhammadiyah Surakarta. Surakarta.

Lendra, M, D dan Santoso, T, B 2009. Beda Pengaruh Kondisi Kaki Datar Dan Kaki Dengan Arkus Normal Terhadap Keseimbangan Statis Pada Anak Usia 8-12 Tahun Di Kelurahan Karangasem, Surakarta. Universitas Muhammadiyah, Surakarta. Jurnal Fisioterapi Vol. 9 No. 2.

Maryatun,. et.al. 2014. Hubungan Pengetahuan Tentang Posyandu Lansia Dan Dukungan Keluarga Dengan Perilaku Mengikuti Posyandu Lansia. Fakultas Kesehatan Masyarakat Universitas Muhammadiyah Semarang.

Nurohman, M, A 2017. Hubungan Tinggi Lompatan dan Bentuk Arcus Pedis dengan Kejadian Sprain Pergelangan Kaki pada Atlet Bulutangkis yang Melakukan Jumping Smash. Universitas Muhammadiyah Semarang

Prasetyo, G, T., Wadji. \& Prasetyo, A, A 2017. Korelasi Antara Body Mass Index Dengan Plantar Arch Index. Fakultas Kedokteran Universitas Diponegoro. Semarang

Radisca, Y 2016. Perbedaan Pengaruh Latihan Penguatan Otot Quadrisep Dengan Otot Dorsal Dan Plantar Fleksor Terhadap Peningkatan
Keseimbangan Dinamis Lansia. Fakulas Ilmu Kesehatan Universitas Muhammadiyah Surakarta.

Rahardianto, A, L., Fathoni, A. \& Hasiholan, L, B 2017. The Effect Of Compensation, Welfare Benefits, Education And Training To Work Productivity In Pt. Multi Servisindo Sarana Substation Semarang (Pengaruh Kompensasi, Tunjangan Kesejahteraan, Pendidikan Dan Pelatihan Pada Pt. Multi Servisindo Sarana Cabang Semarang). Fakultas Ekonomika dan Bisnis Unpand Semarang. Semarang

Sahabuddin, H. 2016. Hubungan Antara Flat Foot Dengan Keseimbangan Dinamis Pada Murid Tk Sulawesi Kota Makassar. Universitas Hasanuddin Makassar.

Sentoso, A, G 2016. Hubungan Antara Obesitas Dengan Keseimbangan Dinamis Pada Lanjut Usia Di Kelurahan Gonilan. Universitas Muhammadiyah Surakarta. Surakarta.

Utomo, B dan Takarini, N 2009. Uji Validitas Kriteria Time Up And Go Test (TUG) Sebagai Alat Ukur Keseimbangan Pada Lansia. Poltekes Depkes Surakarta. Jurnal Fisioterapi Vol. 9 No. 2.

Yuliniarsi, E 2014. Pengaruh Senam Vitalisasi Otak Terhadap Peningkatan Keseimbangan Dinamis Pada Lanjut Usia. Fakultas Ilmu Kesehatan Universitas Muhammadiyah Surakarta. 